\title{
Complementarity of Innovation Policies in the Brazilian Industry: An Econometric Study
}

\author{
Eduardo Strube \\ Marcelo Resende
}

CESIFO WORKING PAPER NO. 2780

CATEGORY 11: INDUSTRIAL ORGANISATION

SEPTEMBER 2009

An electronic version of the paper may be downloaded

- from the SSRN website:

- from the RePEc website:

- from the CESifo website:

www.SSRN.com

Www.RePEc.org

www.CESifo-group.org/wp 


\title{
Complementarity of Innovation Policies in the Brazilian Industry: An Econometric Study
}

\begin{abstract}
The paper aims at assessing discrete complementarities in innovation policies in the context of the Brazilian industry in 2003. The paper considers the approach advanced by Mohnen and and Röller [European Economic Review, 2005] that focuses on supermodularity and submodularity tests for obstacles to innovation (in the present application: lack of finance sources, lack of skilled personnel, lack of cooperation opportunities and lack of information on technology or markets). The application avoids micro-aggregation of the data and explicitly considers sampling weights in the econometric estimation. The analysis highlights the two phases of the innovation process in terms of the propensity and intensity of innovation. The evidence, unlike previous evidence, is not totally clear cut in terms of contrasts of the two phases. Nevertheless one can detect some substitutability and complementarity for specific pairs of obstacles in analysing the propensity to innovate, and strong evidence of complementarities in obstacles when considering the intensity of innovation. In the latter case, therefore, the evidence is suggestive and favours the adoption of more targeted incentive policies.
\end{abstract}

JEL Code: L50, O31, O38.

Keywords: supermodularity, complementarities, innovation.

Eduardo Strube

Petrobrás

Av. República do Chile 63, Centro

200031-012, Rio de Janeiro

Brazil

eduardo.strube@petrobras.com.br
Marcelo Resende

Instituto de Economia

Universidade Federal do Rio de Janeiro

Av. Pasteur 250, Urca

22290-240, Rio de Janeiro-RJ

Brazil

mresende@ie.ufrj.br 


\section{Introduction}

The role of active innovation efforts in fostering economic growth is largely recognized in the endogenous growth literature [see e.g. Romer (1990)] and therefore highlights non-negligible challenges for developing economies to meet the technological gap. In a globalized context the competitive pressure is likely to become more important and increasingly requires the pursual of innovative activities that might require well coordinated government policies. In fact, innovation in developing countries is often incipient and not rarely important multinational firms tend to undertake R\&D investments in their headquarters in other countries.

The Brazilian economy is large and shows the coexistence of technologically dynamic sectors with traditional sectors with low technological effort and constitutes an interesting case for investigating issues associated with the design of innovation policies. A handful of studies, as for example, Resende and Hasenclever (1998), De Negri et al. (2005) and Kannebley et al. (2005) pointed out the reduced technological effort that has prevailed in that economy. A natural question is to what extent active government policies can induce a significant degree of innovation by firms. Indeed, in Brazil a varied set of often uncoordinated incentive policies to innovation have been adopted and comprised special sectoral funds, favourable loans and most notably fiscal incentives policies [see Bastos (2004)].

The different forms of interrelatedness of innovation policies possess distinct policy implications. In that sense, a growing interest has emerged in connection 
with the empirical assessment of complementarities in innovation policies as exemplified by Arora and Gambardella (1990), Arora (1996), Ichniowski et al., (1997) and Miravete and Pernias (2006) in terms of indirect approaches. The possibility of a given innovation activity positively affecting the return of other activities characterizes a complementarity and a direct approach in a discrete setting has been advanced by Mohnen and Röller (2005). The evidence for four European countries indicated that the prevalence of complementarities depend on the phase of the innovation process. The propensity to innovate would be better stimulated by a package of policies whereas the intensity of innovation would call for more specific targeted policies.

The aforementioned approach is promising and is here considered in the context of the Brazilian industries. The motivation for the paper builds on at least three aspects:

a) The scarcity of related works in the context of developing economies;

b) The possibility of avoiding micro-aggregation of the data and the potential related biases;

c) The consideration of estimators that acknowledge the complex sampling of the innovation survey;

The paper is organized as follows. The second section discusses some conceptual aspects associated with the assessment of complementarities in innovation policies and econometric strategies for assessing it. The third section discusses the data source, the empirical model. The fourth section presents the empirical results. The fifth section brings some final comments. 


\section{Complementarity in Innovation}

\section{1- $\underline{\text { Conceptual Aspects }}$}

The empirical assessment of complementarities in innovation activities can be object of a variety of research strategies [see Athey and Stern (1998)) for an overview]. Indirect frameworks include the "correlation approach" and the socalled "reduced form approach". The former approach emphasizes the association between different choice variables with varying degrees of theoretical foundation [see e.g. Arora and Gambardella (1990), Ichniowski et al., (1997) and Miravete and Pernias (2006)] whereas the latter focuses on exclusion restrictions and highlights similar effects of exogenous variables on complementary variables [see e.g. Holmstrom e Milgrom (1994)]

A more direct approach considers special features of an innovation function where complementarities in innovation policy would be associated to the supermodularity of that function. Examples include Mohnen and Röller (2005) and Lokshin et al. (2007). The present paper closely follows the approach advanced by the former authors. The assessment of discrete complementarities requires that one imposes a lattice ordered structure in the domain of the innovation function and evaluates the possibility of supermodularity of that function. ${ }^{1}$ The prevalence of complementarities in innovation policies relates to situations where the whole exceeds the sum of the parts for some innovative outcome variable. Let I(a, $\theta)$ represent a general innovation function where $a=\left(a_{1}, \ldots, a_{k}\right)$ denotes a set of

\footnotetext{
${ }^{1}$ Introductory overviews of the related concepts appear in Milgrom and Roberts (1995) and Vives (1999).
} 
government policies variables and $\theta_{1}$ indicates other relevant control variables that might portray institutional and characteristics that can be firm or sector-specific. Supermodularity of that function would prevail if for all combinations of actions a' and $a^{\prime \prime}$, holds: ${ }^{2}$

$$
I\left(\left(a^{\prime} \wedge a^{\prime \prime}\right), \theta\right)+I\left(\left(a^{\prime} \vee a^{\prime \prime}\right), \theta\right) \geq I\left(a^{\prime}, \theta\right)+I\left(a^{\prime \prime}, \theta\right)
$$

The previous definition is more readily understood if one considers an example with $\mathbf{A}=\{(0,0),(1,1),(0,1),(1,0)\}$. Supermodularity would prevail if $\mathrm{I}(1,0)+\mathrm{I}(0,1) \leq \mathrm{I}(1,1)+\mathrm{I}(0,0)$ or yet $\mathrm{I}(1,0)-\mathrm{I}(0,0) \leq \mathrm{I}(1,1)-\mathrm{I}(0,1)$. This inequality indicates that the reward for increasing a given activity is higher when the other activity is already undertaken. The analysis becomes more complex as the number of inequalities to be considered increases with the number of available policies. A convenient result was advanced by Topkis (1978) and allows to focus on pairwise analyses as a function is supermodular over a subset of its arguments, if and only if all pairwise components in the subset satisfy the previous definition.

In the general case of $\mathrm{k}$ policies there will be $2^{(k-2)} \sum_{i=1}^{k-1} i$ non trivial restrictions to be tested. In particular, in the application considered by Mohnen and Röller (2005) and in the present paper there are 24 restrictions to be considered since $k=4$ in those cases.

In practice, the government policies are often not observed in survey data, and one might need to rely on indirect measures that indicate perceived obstacles to innovation. One would then define $C_{k}=-a_{k}$, where $C_{k}(k=1, \ldots, K)$, indicate the

\footnotetext{
${ }^{2}$ A related relevant concept defines that a function $f$ is said to submodular if $-f$ is supermodular.
} 
innovation obstacles faced by the firm. The innovation function in that case would be given by:

$$
I(C, \theta)=f\left(C_{1},,,,, C_{k}, \theta\right)
$$

In that case where one has inverse proxies for innovation, the interpretation should be more careful. For barriers that have complementarities, specific target policies targeted policies should be considered, whereas the case of a substitution pattern between barriers would call for packages of innovation policies since the reduction of a given barrier exacerbates the effect of the remaining.

\section{2- Empirical Implementation and Econometric Issues}

The aforementioned innovation function can be empirically considered in terms of the expression below:

$$
I_{i}=\sum_{l=0}^{2^{k}-1} \gamma S_{i j}+\beta Z_{i j}+\eta_{j}+\varepsilon_{i}
$$

where, $l_{i}$ represents some outcome of the innovative activity by firm i, $S_{j}$ refers to dummy variables indicating the prevalence of a given combination of policies, $\mathrm{Z}_{t}$ denote the remaining exogenous variables, $\eta_{j}$ and $\varepsilon_{i}$ are respectively sectoral fixed effects and the error term.

A first econometric issue that arise refers to the consistent estimation of equation (3). To address it, one needs to indicate the phase of the innovation process that is being considered. In the investigation of the propensity to innovate one observes data with both innovating and non-innovating firms and therefore standard models for limited dependent variable can be used (for example a probit model). The evaluation of the intensity of innovation, however, is more complex as 
one would observe data on intensity only for innovating firms and therefore one is facing a truncated distribution. A traditional approach is to consider Heckman's two step procedure where the inverse Mills ratio from an initial probit regression with the full sample is regressed as an additional correction term on the final ordinary least squares regression. The procedure known as heckit is often called generalized tobit. ${ }^{3}$

Another aspect that was neglected in the literature pertains the consideration of a weighted maximum likelihood estimation to account for complex sampling design. In fact, survey respondents are selected in accordance with distinct sampling weights and different modern statistical and econometric packages already incorporate the related procedures data [Kish (1965) and Silva et al. (2002) provide useful discussions on complex sampling]

A second econometric issue relates to the implementation of the tests for supermodularity of the innovation function that is considered for pairs of policies. Assuming a total of 4 policies, for policies 1 and 2 one has to face restrictions associated with 4 inequalities (where $X X=\{00,01,10,11\})$ :

$$
\gamma_{10 X X}+\gamma_{01 X X} \leq \gamma_{00 X X}+\gamma_{11 X X}
$$

whereas for pairs 1 and 3 one would have:

$$
\gamma_{1 X 0 X}+\gamma_{0 X 1 X} \leq \gamma_{0 X 0 X}+\gamma_{1 X 1 X}
$$

and for polícies 2 and 3:

$$
\gamma_{X 10 X}+\gamma_{X 01 X} \leq \gamma_{X 00 X}+\gamma_{X 11 X}
$$

\footnotetext{
3 See Greene (2003) for an introductory discussion.
} 
In order to prevail complementarity among policies 1,2 and 3 , it is necessary not to reject the validity of the null hypothesis relating to those restrictions in all tests. Similarly, the same follows in the case of inclusion of the fourth incentive policy.

The hypothesis test needs to consider multiple linear restructions. Letting, with slight abuse of notation, the $\mathrm{k}$ coefficients be represented by the vector $\mathbf{b}$ ( $k x 1$ ), the inequality test assesses the null hypothesis $H_{0}=\mathbf{R} \mathbf{b} \leq 0$ against the alternative hypothesis $\mathrm{H}_{1}=\mathbf{R} \mathbf{b} \geq 0$, where $\mathbf{R}$ is a $p x k$ matrix, $p$ is the number of restrictions, and under the null hypothesis a strict inequaliity holds for at least one of the restrictions. The relevant test statistic is provided by Kodde e Palm (1986)):

$$
c_{w}=(\mathbf{R}(\mathbf{b}-\overline{\mathbf{b}}))^{\mathbf{T}}\left(\mathbf{R} \Omega \mathbf{R}^{\mathrm{T}}\right)^{-1} \mathbf{R}(\mathbf{b}-\overline{\mathbf{b}})
$$

where $\mathbf{b}$ indicates a consistent estimator for the parameter vector and $\overline{\mathbf{b}}$ refers to the estimator that minimizes the previous expression subject to the null hypothesis. Gourieroux et al. (1981) and Wolak $(1989,1991)$ have shown that the appropriate a statistic for such test follows a weighted chi-square distribution. The probability of the test statistic exceeding $c$ under the null hypothesis is given by $\sum_{i} \operatorname{Pr}\left(\chi_{i}{ }^{2} \leq c\right) . w_{i}$, where $w_{i}$ is the relevant weight [see e.g. Shapiro (1985) and Wolak (1989)]. ${ }^{4}$ The relevant critical values appear in table 1 from Kodde e Palm (1986). The lower and upper bounds $\left(c_{l}\right.$ and $c_{u}$ ) at significance levels ranging from 0.25 up to 0.001 and degrees of freedom fro 1 to 40 for tests involving multiple equalities and

\footnotetext{
4 Moreover, Shapiro (1985) shows that those weights add to 1.
} 
inequalities. ${ }^{5}$ If the test statistic lies between $c_{l}$ and $c_{u}$ the test would not be conclusive. It is important to stress that consistent estimation of the coefficients is required for implementing the test and potential endogeneities could pose an important challenge. Mohnen e Röller (2005), however, ponder that such caveat does not directly jeopardizes the analysis as even with inconsistent estimates, the error term would be correlated with the interaction terms and not with the practices themselves.

\section{Empirical Analysis}

\section{1- Data}

The study relies on a comprehensive survey on technological innovation in the context of the Brazilian industry [Pesquisa de Inovação Tecnológica-PINTEC, Instituto Brasileiro de Geografia e Estatística-IBGE].6 The referred survey considers active firms with main revenues associated with extractive or manufacturing industry and with 10 or more employees. We were granted special access to the micro data of PINTEC-2003. It is important to stress that the questionnaire closely follows the one from the Community Innovation Survey (CIS 1) that was conducted for European countries and used by Mohnen and Röller (2005). Nevertheless, it is worth emphasizing that in the Brazilian case one does not face a micro-aggregation limitation. The survey was carried out in 2000, 2003

\footnotetext{
5 Following Kodde and Palm (1986), the degrees of freedom equal one plus the number of equalities tested for the lower bound and the total number of equalities and inequalities for the upper bound.

6 The questionnaire and other details are presented in IBGE (2005)
} 
and 2005. The quantitative data and a few qualitative ones (like for example unfinshed projects) refer to the current year of the survey. The majority of the qualitative data refer to the period of the current year and the 2 consecutive previous one (in the case of PINTEC-2003, from 2001 until 2003).

A stratified sampling procedure is adopted where the first stratum is defined in accordance with the probability of the firm being an innovator. The allocation of a firm to a stratum depends on a set of indicators (primary and secondary). The first subset, the certain stratum, comprises large firms (with 500 or more employees) or yet firms that had declared themselves as innovators in the previous edition of the survey that are included with probability 1.

Two additional classes of stratum are considered in terms of the eligible and non-eligible categories, In the former one includes firms with reasonable chances of being innovators whereas in the latter one includes firms with slim or none chance of being innovators.

In order to guarantee reliable information for the different regions, a second stratum level considered different cut-off points depending on the importance of the economic activity. In the case of the most important industrial state (São Paulo), for example the criterion was $80 \%$ of the industrial transformation value. The selection of the sample in the final stratum considers selection probability that is proportional to the square root of the number of employees. Altogether, the previous observations indicate a complex stratified sampling that should be acknowledged in the estimation as the Brazilian case is characterized by non-negligible sectoral and geographical heterogeneities. 
Prior to defining the sample, we excluded firms with R\&D intensity above $50 \%$ that could be outliers, Moreover, sectoral dummies were considered in terms of 16 industrial sector was considered (in terms of the Classificação Nacional de Atividades Econômicas-CNAE-IBGE). The referred sectors are listed in the appendix. Next we describe the variables considered in the econometric estimation.

Table 1 - Definition of variables

\begin{tabular}{|c|c|}
\hline \multicolumn{2}{|r|}{ Endogenous variables: } \\
\hline \multicolumn{2}{|c|}{$\begin{array}{l}\text { Propensity to innovate } \\
\text { product, for the market or only for the firm, and. } 0 \text { otherwise. } \\
\text { Intensity of innovation } \\
\text { Revenues from innovating products divided by total revenues when the main } \\
\text { market is national, and net exports of innovating products divided by total } \\
\text { exports when the main market is abroad. }\end{array}$} \\
\hline \multicolumn{2}{|r|}{ Exogenous variables: } \\
\hline $\log (E M P)$ & Logarithm of the number of employees. \\
\hline Foreign & $\begin{array}{l}\text { Dummy variable assumes value } 1 \text { if the firm has dominant share of foreign } \\
\text { capital and } 0 \text { otherwise }\end{array}$ \\
\hline Group & $\begin{array}{l}\text { Dummy variable assumes value } 1 \text { if the firm is part of a group and } 0 \\
\text { otherwise. }\end{array}$ \\
\hline Organizational & $\begin{array}{l}\text { Dummy variable assumes value } 1 \text { if the firm implemented a significant } \\
\text { organizational change and } 0 \text { otherwise. }\end{array}$ \\
\hline Exporting & Dummy variable assumes value 1 if the firm exports and 0 otherwise. \\
\hline$R \& D$ intensity & R\&D expenses divided by net sales revenues \\
\hline Continuous & $\begin{array}{l}\text { Dummy variable assumes value } 1 \text { if the firm makes continuous R\&D } \\
\text { expenditures and } 0 \text { otherwise. }\end{array}$ \\
\hline Cooperation & $\begin{array}{l}\text { Dummy variable assumes value } 1 \text { if the firm cooperates with other institutions } \\
\text { and } 0 \text { otherwise. }\end{array}$ \\
\hline Sectoral dummies & Dummy variables for the sectors listed in the appendix \\
\hline Regional dummies & $\begin{array}{l}\text { Dummy variables for the Brazilian macro regions (North, Midwest, Northeast, } \\
\text { Southeast, South) }\end{array}$ \\
\hline \multicolumn{2}{|r|}{ Obstacles to innovation (dummy variables constructed upon combinations) } \\
\hline 01 & Lack of appropriate finance sources \\
\hline 02 & Lack of skilled personnel \\
\hline O3 & Lack of opportunities for cooperation with other firms/institutions \\
\hline 04 & Lack of information on technology or on the market \\
\hline
\end{tabular}

The variables are similar to those considered in Mohnen and Röller (2005), As for policies variables we also focus on perceived obstacles to innovation, but consider the categories referring to risk and finance, knowledge-skill within 
enterprise and Knowledge-skill outside the enterprise, In the first category we considered the obstacle referring to the lack of appropriate sources of finance. In the second category, we considered the lack of skilled personnel and lack of information on technology or on the market. In the third category, we focused on the lack of opportunities for cooperation with other firms/institutions. Next, tables 2 and 3 display some basic summary statistics and indicate substantial heterogeneity,

Table 2 - Summary statistics (expanded sample ${ }^{7}$ )

\begin{tabular}{ccccc} 
& \multicolumn{3}{c}{ Std. } \\
& Mean & error & Confidence interval 95\% \\
\hline Propensity to innovate & 0.330 & 0.007 & 0.315 & 0.344 \\
Intensity of innovation & 0.088 & 0.004 & 0.080 & 0.096 \\
Number of employees & 49.08 & 0.690 & 47.71 & 50.44 \\
\hline \multicolumn{2}{c}{ Source: PINTEC-IBGE 2003 }
\end{tabular}

Table 3 - Summary statistics (expanded sample)

Did not innovate

\begin{tabular}{c|ccccccccc}
\hline & Mean & Std. error & \multicolumn{1}{c}{ Confidence interval 95\% } & Mean & Std. error & Confidence interval 95\% \\
\hline Foreign & 0.014 & 0.002 & 0.011 & 0.017 & 0.030 & 0.002 & 0.025 & 0.034 \\
Group & 0.025 & 0.002 & 0.020 & 0.029 & 0.043 & 0.004 & 0.035 & 0.050 \\
Organizational & 0.584 & 0.010 & 0.565 & 0.603 & 0.834 & 0.010 & 0.813 & 0.854 \\
R\&D intensity & - & - & - & - & 0.007 & 0.001 & 0.005 & 0.008 \\
Continuous & - & - & - & - & 0.071 & 0.005 & 0.062 & 0.080 \\
Cooperation & - & - & - & - & 0.029 & 0.003 & 0.022 & 0.036 \\
\hline
\end{tabular}

\section{Source: PINTEC-IBGE, 2003}

\footnotetext{
${ }^{7}$ Summary statistics of the sample are available upon request
} 
Table 4, in particular, provides an idea of the relative importance of the perceived obstacles to innovation.

Table 4 - Relative frequency of obstacles to innovation (expanded sample)

\begin{tabular}{lr}
\hline No obstacle was encountered & $69.00 \%$ \\
Finance source & $28.16 \%$ \\
Skilled personnel & $12.80 \%$ \\
Opportunities for cooperation with other firms/institutions & $7.88 \%$ \\
Information on technology or market & $12.30 \%$ \\
High economic risks & $24.74 \%$ \\
Scarcity of adequate technological services & $6.67 \%$ \\
\hline Source: PINTEC-IBGE, 2003
\end{tabular}

\section{Empirical Analysis}

In this section we present the empirical results from the econometric estimation that were carried out with Stata SE 10.0.An important feature of that software is that it allows to incorporate sampling weights in the maximum likelihood estimation. The related results appear in tables 5 and 6 . For conciseness reasons, we do not report the results regarding the sectoral and regional dummies, but important differences emerge when comparing estimates that incorporate complex sampling or not. We will use the results that incorporate sampling weights as presented in table 5 as our preferential results. The results depends on the phase of the innovation process, In the equation referring to the propensity of innovation the regional dummies exert no significant effect when one considers individual coefficients, In the case of sectoral dummies only coefficient is clearly significant and two others are marginally significant. As for the variables indicating combination of obstacles we will not emphasize the discussion of individual coefficients but rather discuss complementarity tests later in this section. Some 
other plausible results emerge in terms of positive and significant coefficients for the firm size variable (LEMP), the organizational change variable and for the exporting variables that is denotative of competitive pressures.

When one considers the intensity of innovation, the previous results essentially prevail but additionally one observes a clearly significant positive coefficient for organizational change, Moreover, if a significance level slightly above $5 \%$ is considered, it is possible to detect important positive effects accruing from ownership, participation in groups and R\&D intensity.

Next, we consider the main issue of the paper namely that of testing for the presence of complementarities in innovation policies (or obstacles to innovation). ${ }^{8}$ The interpretation of the test statistics reported in table 7 run as follows. Values above the upper bound critical value at a $10 \%$ as given by 7.094 indicate a rejection of the null hypothesis. Values below lower bound critical value of 1.642 would favour acceptance of hypothesis, whereas intermediate values between the referred bounds would indicate that the test is inconclusive. When the test focuses on supermodularity, acceptance of the null hypothesis would indicate the prevalence of complementarity in obstacles to innovation. When submodularity is considered instead, the acceptance of the null hypothesis would signal the presence of substitutability in obstacles to innovation.

In the study of Mohnen and Röller (2005) the results were clear cut in the sense that in general substitutability in obstacles to innovation prevailed when considering the propensity to innovate and complementarity was salient when one

\footnotetext{
${ }^{8}$ We thank Pierre Mohnen for kindly providing the Gauss code for implementing the inequality restrictions tests.
} 
considers the intensity of innovation. In the present investigation the results are less clear.

Starting with the assessment of the propensity to innovate the results are not strong and do not spread along several different pairs of obstacles. There is evidence of complementary of obstacles between the lack of information on technology or markets (OBS4) and lack of skilled personnel (OBS2) and yet lack of cooperation opportunities (OBS3). For example, for the pair of obstacles 2-4 the test statistic would be 0.321 and favour supermodularity (complementarity). The test for submodularity, on the other hand, only favours the acceptance of the null hypothesis of substitutability between lack of finance sources and lack of information (pair 1-4).

When we consider the intensity of innovation, the results are stronger. In the case of the test for supermodularity we cannot reject the null hypothesis for any of the pairs (the largest value for the test statistics was 1.593 for pair 2-3). As for the test of submodularity evidence indicates substitutability between lack of cooperation opportunities with both lack of finance sources and lack of skilled personnel (respectively pairs $1-3$ and $2-3$ ). Please note that pair 2-3 shows ambivalent evidence and given the generous confidence level adopted one should refrain from a strong conclusion in that case. Finally, submodularity appears to prevail between lack of cooperation opportunities and lack of information (pair 3-4).

Altogether, the evidence contrasts somewhat with previous evidence for European counties. In particular, there is only limited evidence for substitutability or complementarity for few pairs of obstacles. When one considers the intensity of 
innovation the evidence strongly indicates the presence of complementary obstacles,

Table 5 - Regression results (models using sampling weights)

\begin{tabular}{lccc|ccc}
\hline \multirow{2}{*}{ Variables } & \multicolumn{3}{c|}{ Propensity to innovate } & \multicolumn{3}{c}{ Intensity of innovation } \\
\cline { 2 - 6 } & coef. & std. error & p-value & coef. & std. error & p-value \\
\hline Log(EMP) & 0.091 & 0.021 & 0.000 & -0.044 & 0.009 & 0.000 \\
Foreign & 0.087 & 0.089 & 0.332 & 0.055 & 0.029 & 0.061 \\
Group & 0.097 & 0.093 & 0.297 & 0.072 & 0.040 & 0.074 \\
Organizational & 0.649 & 0.052 & 0.000 & -0.145 & 0.033 & 0.000 \\
Exporting. & 0.205 & 0.054 & 0.000 & -0.044 & 0.023 & 0.055 \\
R\&D intensity & - & - & - & 0.504 & 0.267 & 0.059 \\
Continuous & - & - & - & 0.023 & 0.024 & 0.342 \\
Cooperation & - & - & - & 0.035 & 0.038 & 0.348 \\
States: & & & & & & \\
0001 & -0.742 & 0.444 & 0.095 & 0.288 & 0.167 & 0.087 \\
0010 & -0.150 & 0.692 & 0.828 & 0.676 & 0.274 & 0.014 \\
0011 & 1.650 & 0.715 & 0.021 & 0.291 & 0.169 & 0.085 \\
0100 & -0.021 & 0.472 & 0.964 & 0.398 & 0.162 & 0.014 \\
0101 & 0.318 & 0.474 & 0.503 & 0.362 & 0.155 & 0.020 \\
0110 & -0.759 & 0.725 & 0.295 & 0.286 & 0.220 & 0.193 \\
0111 & 0.342 & 0.677 & 0.613 & 0.442 & 0.211 & 0.036 \\
1000 & -0.808 & 0.341 & 0.018 & 0.473 & 0.154 & 0.002 \\
1001 & -0.699 & 0.356 & 0.050 & 0.426 & 0.156 & 0.006 \\
1010 & -0.739 & 0.380 & 0.052 & 0.531 & 0.168 & 0.002 \\
1011 & -0.488 & 0.372 & 0.189 & 0.429 & 0.167 & 0.010 \\
1100 & -0.916 & 0.353 & 0.009 & 0.503 & 0.160 & 0.002 \\
1101 & -0.323 & 0.350 & 0.356 & 0.453 & 0.155 & 0.004 \\
1110 & -0.459 & 0.384 & 0.231 & 0.511 & 0.172 & 0.003 \\
1111 & -0.198 & 0.353 & 0.574 & 0.404 & 0.155 & 0.009 \\
0000 & -1.073 & 0.336 & 0.001 & 0.489 & 0.152 & 0.001 \\
\hline Lambda & & & & 0,0249 & 0.0143 & 0.041 \\
\hline & & & & & &
\end{tabular}


Table 6 - Regression results (models not using sampling weights)

\begin{tabular}{|c|c|c|c|c|c|c|}
\hline \multirow{2}{*}{ Variables } & \multicolumn{3}{|c|}{ Propensity to innovate } & \multicolumn{3}{|c|}{ Intensity of innovation } \\
\hline & coef. & std. error & $p$-value & coef. & std. error & $p$-value \\
\hline $\log (E M P)$ & 0.138 & 0.013 & 0.000 & 0.007 & 0.015 & 0.650 \\
\hline Foreign & 0.122 & 0.059 & 0.037 & 0.085 & 0.029 & 0.003 \\
\hline Group & -0.010 & 0.051 & 0.851 & 0.036 & 0.025 & 0.148 \\
\hline Organizational & 0.679 & 0.035 & 0.000 & 0.176 & 0.080 & 0.027 \\
\hline Exporting. & 0.249 & 0.035 & 0.000 & 0.051 & 0.030 & 0.088 \\
\hline$R \& D$ intensity & & & & 0.386 & 0.202 & 0.056 \\
\hline Continuous & & & & 0.047 & 0.017 & 0.005 \\
\hline Cooperation & & & & 0.042 & 0.024 & 0.070 \\
\hline States: & & & & & & \\
\hline 0001 & -1.600 & 0.290 & 0.000 & -0.680 & 0.335 & 0.043 \\
\hline 0010 & -1.156 & 0.481 & 0.016 & -0.226 & 0.341 & 0.508 \\
\hline 0011 & -0.481 & 0.585 & $0 ; 411$ & -0.342 & 0.307 & 0.266 \\
\hline 0100 & -0.632 & 0.306 & 0.039 & -0.372 & 0.264 & 0.159 \\
\hline 0101 & -0.621 & 0.326 & 0.057 & -0.471 & $0 ; 265$ & 0.076 \\
\hline 0110 & -1.349 & 0.498 & 0.007 & -0.231 & 0.370 & 0.533 \\
\hline 0111 & -0.810 & 0.437 & 0.064 & -0.269 & 0.301 & 0.371 \\
\hline 1000 & -1.503 & 0.218 & 0.000 & -0.626 & 0.314 & 0.047 \\
\hline 1001 & -1.364 & 0.229 & 0.000 & -0.564 & 0.304 & 0.064 \\
\hline 1010 & -1.418 & 0.241 & 0.000 & -0.532 & 0.312 & 0.088 \\
\hline 1011 & -1.232 & 0.245 & 0.000 & -0.529 & 0.297 & 0.077 \\
\hline 1100 & $-1,435$ & 0.228 & 0.000 & $-0,542$ & 0.310 & 0.080 \\
\hline 1101 & -1.086 & 0.225 & 0.000 & -0.472 & 0.280 & 0.092 \\
\hline 1110 & -1.239 & 0.252 & 0.000 & -0.530 & 0.299 & 0.076 \\
\hline 1111 & -0.964 & 0.228 & 0.000 & -0.452 & 0.272 & 0.097 \\
\hline 0000 & -1.868 & 0.215 & 0.000 & -0.722 & 0.349 & 0.038 \\
\hline Lambda & & & & 0.531 & 0.1576988 & 0.001 \\
\hline
\end{tabular}

Table 7 - Wald tests for inequality restrictions (at the $10 \%$ significance level, the lower bound is given by 1.642 and the upper bound is given by 7.094) - Obstacles to innovation

\begin{tabular}{|c|c|c|c|c|c|c|c|c|c|c|c|c|}
\hline \multirow[b]{2}{*}{$\begin{array}{l}\text { Pair of } \\
\text { obstacles }\end{array}$} & \multicolumn{6}{|c|}{$\begin{array}{l}\text { Propensity to } \\
\text { innovate }\end{array}$} & \multicolumn{6}{|c|}{ Intensity of innovation } \\
\hline & $1-2$ & $1-3$ & $1-4$ & $2-3$ & $2-4$ & $3-4$ & $1-2$ & $1-3$ & $1-4$ & $2-3$ & $2-4$ & $3-4$ \\
\hline & \multicolumn{12}{|c|}{ Supermodularity test: } \\
\hline & 12.826 & 10.766 & 4.238 & 9.148 & 0.321 & 1.555 & 1.145 & 0.918 & 1.26 & 1.593 & 0.002 & 1.038 \\
\hline & \multicolumn{12}{|c|}{ Submodularity test: } \\
\hline
\end{tabular}

Definition of obstacles: 1 - Lack of appropriate finance sources; 2 - Lack of skilled personnel; 3 - Lack of opportunities for cooperation with other firms/institutions; 4 - Lack of information on technology or on the market 


\section{Final Comments}

The paper aimed at investigating the presence of complementarities in innovation policies in the Brazilian industry in term of inverse proxies for innovation (obstacles). The paper benefits from micro-data that are not subject to limitations related to micro-aggregation and explicitly considered sampling weights in the estimations. The analysis considered tests fot supermodularity and submodularity of an innovation function taking as references obstacles to innovation referring to lack of adequate finance sources, lack of skilled personnel, lack of opportunities for cooperation with other firms/institutions and lack of information on technology or on the market. The study highlighted the different phases of the innovation process in terms of the propensity of innovation (in terms of a Probit model) and the intensity of innovation (in terms of a generalized Tobit model).

The results did not indicate clear distinct patterns in the two phases of the innovation process like in Mohnen and Röller (2005). In fact, we find limited evidence favouring substitutability and complementarity in obstacles in the case of the propensity to innovate. Specifically, there is some evidence that suggests the relevance of a package of policies relating to finance sources and information on technology or the market. On the other hand, if we consider the intensity of innovation the evidence is stronger and indicates complementarities of obstacles and the need for more targeted policies.

Even though the results are suggestive, stronger policy recommendations would be clearer if further research combines different years of that survey in the future. Additionally, the reliance on an indirect approach based on obstacles to innovations has shortcomings. Indeed, the perception that innovation has been 
curbed by some particular obstacle can be subjective as one is not sure that an innovation would actually occur if that barrier did not prevail. A relevant extension should consider direct measures reflecting actual incentive policies for innovation, what of course would require better data. 


\section{References}

Arora. A. (1996). Testing for complementarities in reduced-form regressions: a note. Economics Letters. 50. 51-55

Arora. A.. Gambardella. A. (1990). Complementarity and external linkages: the strategies of the large firms in biotechnology. Journal of Industrial Economics. 38. $361-379$

Arora. A.. Gambardella. A. (1994). Evaluating technological information and utilizing it: Scientific knowledge. technological capability and external linkages in biotechnology. Journal of Economic Behavior and Organization. 91-114

Athey. S.. Stern. S. (1998). An empirical framework for testing theories about complementarity in organizational design. NBER working paper no. 6600 Bastos, V. D. (2004), Incentivo à inovação: tendências internacionais e no Brasil. Revista do BNDES, 11, 107-138

Gouriéroux, C., Holly, A., Monfort, A. (1982), Likelihood ratio test. Wald test. and Kuhn-Tucker test in linear models with inequality constraints on the regression parameters, Econometrica, 50, 63-80

Greene, W.H. (2003), Econometric Analysis, Upper Saddle Rivers: Prentice-Hall Holmström, B., Milgrom, P. (1994), The firm as an incentive system, American Economic Review, 84, 972-991

IBGE (2005), Pesquisa Industrial de Inovação Tecnológica 2003. Rio de Janeiro: IBGE, http://www.ibge.gov.br/home/estatistica/economia/industria/pintec/2003/pintec2003.pdf Ichniowski. C., Shaw. K. Prennushi. G. (1997), The Effects of Human Resource Management Practices on Productivity, American Economic Review, 87, 291-313. 
Kannebley Jr.. S.. Porto. G.S.. Pazello. E.T. (2005). Characteristics of Brazilian innovative firms: an empirical analysis based on PINTEC - industrial research on technological innovation. Research Policy. 34. 872-893

Kish, L. (1965), Survey Sampling, New York: John Wiley

Kodde. D.A.. Palm. F.C. (1986). Wald criteria for jointly testing equality and inequality restrictions. Econometrica. 54. 1243-1248

Shapiro. A. (1985), Asymptotic distribution of test statistics in the analysis of moment structures under inequality constraints, Biometrika, 72, 133-44

Lokshin. B., Carree, M. Belderbos, R. (2007), Testing for complementarity and substitutability in case of multiple practices, Katholieke Universiteit Leuven, MSI 0708

Milgrom. P.. Roberts. J. (1995). Complementarities and fit: strategy. structure and organizational change in manufacturing. Journal of Accounting and Economics. 19. $179-208$

Miravete. E. J.. Pernias. J. C. (2006). Innovation complementarity and scale of production. Journal of Industrial Economics. 54. 1-29

Mohnen. P.. Röller. L.H. (2005). Complementarities in innovation policies. European Economic Review. 49. 1431-1450

Resende. M.. Hasenclever. L. (1998). Intensidade em pesquisa e desenvolvimento e tamanho da firma: uma análise exploratória do caso brasileiro. Estudos Econômicos. 28. 601-618 Romer. P. (1990). Endogenous technological change. Journal of Political Economy. 98. 71-102 
Silva. P.L.N.. Pessoa, D.G.C., Lilá, M. F. (2002), Análise estatística de dados da PNAD incorporando a estrutura do plano amostral, Ciência \& Saúde Coletiva, 7 , $659-670$

Topkis. D.M. (1978). Minimizing a submodular function on a lattice, Operations Research. 26, 305-321

Vives. X. (1999). Oligopoly Pricing: Old Ideas and New Tools. Cambridge: MIT Press

Wolak. F. (1989). Testing inequality constraints in linear econometric models. Journal of Econometrics. 41. 205-35

Wolak. F. (1991). The local nature of hypothesis tests involving inequality constraints in nonlinear models. Econometrica. 59. 981-95 


\section{Appendix}

Definitions of the industrial sectors

\begin{tabular}{lccc} 
& \multicolumn{3}{c}{ Number of } \\
Sector & CNAE codes & firms & $\%$ \\
\hline Extractive & $10,11,13,14$ & 1863 & $2,25 \%$ \\
Food, drinks and tobacco & 15 e 16 & 10400 & $12,56 \%$ \\
Textile & 17 & 3089 & $3,73 \%$ \\
Clothing & 18 & 11592 & $14,00 \%$ \\
Leather & 19 & 3792 & $4,58 \%$ \\
Wood products & 20 & 5010 & $6,05 \%$ \\
Cellulose, paper and printing & 21 e 22 & 5274 & $6,37 \%$ \\
Coke, fuel & 23 & 166 & $0,20 \%$ \\
Chemicals & 24 & 3329 & $4,02 \%$ \\
Pharmaceuticals & 25 & 4968 & $6,00 \%$ \\
Non-metallic minerals & 26 & 6632 & $8,01 \%$ \\
Metallurgy and metal products & 27 e 28 & 8727 & $10,54 \%$ \\
Machinery and equipments & 29 & 5332 & $6,44 \%$ \\
Electric and electronic machinery and equipment & $30,31,32,33$ & 3296 & $3,98 \%$ \\
Transportation vehicles and others & 34 e 35 & 2360 & $2,85 \%$ \\
Others & 36 e 37 & 6972 & $8,42 \%$ \\
\hline Total & & $\mathbf{8 2 . 8 0 2}$ & $\mathbf{1 0 0 , 0 0 \%}$ \\
\hline
\end{tabular}

Source: own elaboration upon data from PINTEC-IBGE, 2003 


\section{CESifo Working Paper Series}

for full list see www.cesifo-group.org/wp

(address: Poschingerstr. 5, 81679 Munich, Germany, office@cesifo.de)

2717 Ben J. Heijdra and Jochen O. Mierau, Annuity Market Imperfection, Retirement and Economic Growth, July 2009

2718 Kai Carstensen, Oliver Hülsewig and Timo Wollmershäuser, Price Dispersion in the Euro Area: The Case of a Symmetric Oil Price Shock, July 2009

2719 Katri Kosonen and Gaëtan Nicodème, The Role of Fiscal Instruments in Environmental Policy, July 2009

2720 Guglielmo Maria Caporale, Luca Onorante and Paolo Paesani, Inflation and Inflation Uncertainty in the Euro Area, July 2009

2721 Thushyanthan Baskaran and Lars P. Feld, Fiscal Decentralization and Economic Growth in OECD Countries: Is there a Relationship?, July 2009

2722 Nadia Fiorino and Roberto Ricciuti, Interest Groups and Government Spending in Italy, 1876-1913, July 2009

2723 Andreas Wagener, Tax Competition, Relative Performance and Policy Imitation, July 2009

2724 Hans Fehr and Fabian Kindermann, Pension Funding and Individual Accounts in Economies with Life-cyclers and Myopes, July 2009

2725 Ernesto Reuben and Arno Riedl, Enforcement of Contribution Norms in Public Good Games with Heterogeneous Populations, July 2009

2726 Kurt Schmidheiny and Marius Brülhart, On the Equivalence of Location Choice Models: Conditional Logit, Nested Logit and Poisson, July 2009

2727 Bruno S. Frey, A Multiplicity of Approaches to Institutional Analysis. Applications to the Government and the Arts, July 2009

2728 Giovanni Villani, A Strategic R\&D Investment with Flexible Development Time in Real Option Game Analysis, July 2009

2729 Luca Di Corato and Michele Moretto, Investing in Biogas: Timing, Technological Choice and the Value of Flexibility from Inputs Mix, July 2009

2730 Gilad D. Aharonovitz, Nathan Skuza and Faysal Fahs, Can Integrity Replace Institutions? Theory and Evidence, July 2009

2731 Michele Moretto and Sergio Vergalli, Managing Migration through Conflicting Policies: an Option-theory Perspective, July 2009 
2732 Volker Nitsch, Fly or Cry: Is Airport Noise Costly?, July 2009

2733 Francesco Cinnirella and Joachim Winter, Size Matters! Body Height and Labor Market Discrimination: A Cross-European Analysis, July 2009

2734 Samuel Bowles and Sandra Polanía Reyes, Economic Incentives and Social Preferences: A Preference-based Lucas Critique of Public Policy, July 2009

2735 Gary Burtless, Lessons of the Financial Crisis for the Design of National Pension Systems, July 2009

2736 Helmuth Cremer, Firouz Gahvari and Pierre Pestieau, Fertility, Human Capital Accumulation, and the Pension System, July 2009

2737 Hans Jarle Kind and Frank Stähler, Market Shares in Two-Sided Media Industries, July 2009

2738 Pamela Campa, Alessandra Casarico and Paola Profeta, Gender Culture and Gender Gap in Employment, August 2009

2739 Sebastian Gechert, Supplementary Private Health Insurance in Selected Countries: Lessons for EU Governments?, August 2009

2740 Leif Danziger, Endogenous Monopsony and the Perverse Effect of the Minimum Wage in Small Firms, August 2009

2741 Yan Dong and John Whalley, A Third Benefit of Joint Non-OPEC Carbon Taxes: Transferring OPEC Monopoly Rent, August 2009

2742 Valentina Bosetti, Carlo Carraro and Massimo Tavoni, Climate Change Mitigation Strategies in Fast-Growing Countries: The Benefits of Early Action, August 2009

2743 Christina Felfe, The Willingness to Pay for Job Amenities: Evidence from Mothers' Return to Work, August 2009

2744 Jörg Franke, Christian Kanzow, Wolfgang Leininger and Alexandra Väth, Effort Maximization in Asymmetric N-Person Contest Games, August 2009

2745 Bruno S. Frey and Paolo Pamini, Making World Heritage Truly Global: The Culture Certificate Scheme, August 2009

2746 Frank N. Caliendo, Is Social Security behind the Collapse of Personal Saving?, August 2009

2747 Caterina Liesegang and Marco Runkel, Corporate Income Taxation of Multinationals and Fiscal Equalization, August 2009

2748 Chrysovalantou Milliou and Apostolis Pavlou, Upstream Horizontal Mergers and Efficiency Gains, August 2009 
2749 Rüdiger Pethig and Christian Wittlich, Interaction of Carbon Reduction and Green Energy Promotion in a Small Fossil-Fuel Importing Economy, August 2009

2750 Kai Carstensen, Oliver Hülsewig and Timo Wollmershäuser, Monetary Policy Transmission and House Prices: European Cross-country Evidence, August 2009

2751 Olaf Posch, Explaining Output Volatility: The Case of Taxation, August 2009

2752 Beatrice Scheubel, Daniel Schunk and Joachim Winter, Don't Raise the Retirement Age! An Experiment on Opposition to Pension Reforms and East-West Differences in Germany, August 2009

2753 Daniel G. Arce, Dan Kovenock and Brian Roberson, Suicide Terrorism and the Weakest Link, August 2009

2754 Mario Larch and Wolfgang Lechthaler, Comparative Advantage and Skill-Specific Unemployment, August 2009

2755 Horst Raff and Nicolas Schmitt, Buyer Power in International Markets, August 2009

2756 Seppo Kari, Hanna Karikallio and Jukka Pirttilä, The Impact of Dividend Taxation on Dividends and Investment: New Evidence Based on a Natural Experiment, August 2009

2757 Mirco Tonin and Michael Vlassopoulos, Disentangling the Sources of Pro-social Behavior in the Workplace: A Field Experiment, August 2009

2758 Nicole Grunewald and Inmaculada Martínez-Zarzoso, Driving Factors of Carbon Dioxide Emissions and the Impact from Kyoto Protocol, August 2009

2759 Yu-Fu Chen and Michael Funke, Booms, Recessions and Financial Turmoil: A Fresh Look at Investment Decisions under Cyclical Uncertainty, August 2009

2760 Jan-Egbert Sturm and Jakob de Haan, Does Central Bank Communication really Lead to better Forecasts of Policy Decisions? New Evidence Based on a Taylor Rule Model for the ECB, August 2009

2761 Larry Karp, Sacrifice, Discounting and Climate Policy: Five Questions, August 2009

2762 Marianna Belloc and Samuel Bowles, International Trade, Factor Mobility and the Persistence of Cultural-Institutional Diversity, August 2009

2763 Charles Noussair and Fangfang Tan, Voting on Punishment Systems within a Heterogeneous Group, August 2009

2764 Birgit Bednar-Friedl and Karl Farmer, Internationally Coordinated Emission Permit Policies: An Option for Withdrawers from the Kyoto Protocol?, August 2009

2765 Pierre M. Picard and David E. Wildasin, Labor Market Pooling, Outsourcing and Labor Contracts, August 2009 
2766 Stefan Voigt and Lorenz Blume, The Economic Effects of Federalism and Decentralization - A Cross-Country Assessment, August 2009

2767 David S. Jacks, Christopher M. Meissner and Dennis Novy, Trade Booms, Trade Busts, and Trade Costs, August 2009

2768 Mario Jametti and Thomas von Ungern-Sternberg, Hurricane Insurance in Florida, August 2009

2769 Alessandro Balestrino, Kind of Black: The Musicians' Labour Market in Italy, August 2009

2770 Yosr Abid Fourati and Cathal O’Donoghue, Eliciting Individual Preferences for Pension Reform, August 2009

2771 Christian Breuer and Chang Woon Nam, VAT on Intra-Community Trade and Bilateral Micro Revenue Clearing in the EU, August 2009

2772 Choudhry Tanveer Shehzad, Jakob De Haan and Bert Scholtens, Growth and Earnings Persistence in Banking Firms: A Dynamic Panel Investigation, August 2009

2773 Erdal Yalcin, Uncertain Productivity Growth and the Choice between FDI and Export, August 2009

2774 Klaus Abberger, Wolfgang Nierhaus and Shynar Shaikh, Findings of the Signal Approach for Financial Monitoring in Kazakhstan, September 2009

2775 Sascha O. Becker, Francesco Cinnirella and Ludger Woessmann, The Trade-off between Fertility and Education: Evidence from before the Demographic Transition, September 2009

2776 Thomas Aronsson and Erkki Koskela, Optimal Income Taxation, Outsourcing and Policy Cooperation in a Dynamic Economy, September 2009

2777 Joel Slemrod, Old George Orwell Got it Backward: Some Thoughts on Behavioral Tax Economics, September 2009

2778 Cagri Seda Kumru and Athanasios C. Thanopoulos, Social Security Reform and Temptation, September 2009

2779 Alessandro Bucciol and Roel M. W. J. Beetsma, Inter- and Intra-generational Consequences of Pension Buffer Policy under Demographic, Financial and Economic Shocks, September 2009

2780 Eduardo Strube and Marcelo Resende, Complementarity of Innovation Policies in the Brazilian Industry: An Econometric Study, September 2009 